\title{
A study on the relationships between corrosion properties and chemistry of thermally oxidised surface films formed on polished commercial magnesium alloys $A Z 31$ and $A Z 61$
}

Sebastián Feliu (Jr) ${ }^{\mathrm{a}}$, Alejandro Samaniego ${ }^{\mathrm{a}}$, Violeta Barranco ${ }^{\mathrm{b}}$, A.A. El-Hadad ${ }^{\mathrm{c}}$, Irene Llorente ${ }^{\mathrm{a}}$, Carmen Serra ${ }^{\mathrm{d}}$ and J.C. Galván ${ }^{\mathrm{a}}$

${ }^{a}$ Centro Nacional de Investigaciones Metalúrgicas CSIC, Avda. Gregorio del Amo 8, 28040 Madrid, Spain, (e-mail: sfeliu@cenim.csic.es)

bInstituto de Ciencias de Materiales de Madrid, ICMM, Consejo Superior de Investigaciones Científicas, CSIC, Sor Juana Inés de la Cruz, 3, Cantoblanco, 28049, Madrid, Spain.

'Physics Department, Faculty of Science, Al-Azhar University,Nasr City 11884, Cairo, Egypt.

${ }^{d}$ Servicio de Nanotecnologia y Análisis de Superficies, CACTI, Universidade de Vigo, 36310 Vigo, Spain

Corresponding author: Tel.: +34 91 5538900. Fax.: +34 91 5347425. Email address: sfeliu@cenim.csic.es

Abstract: This paper studies the changes in chemical composition of the thin oxide surface films induced by heating in air at $200^{\circ} \mathrm{C}$ for time intervals from 5 minutes up to 60 minutes on the freshly polished commercial AZ31 and AZ61 alloys with a view to better understanding their protective properties. This thermal treatment resulted in the formation of layers enriched in metallic aluminium at the interface between the outer $\mathrm{MgO}$ surface films and the bulk material. A strong link was found between the degree of metallic Al enrichment in the subsurface layer (from 10 to 15 at \%) observed by XPS (X-ray photoelectron spectroscopy) in the AZ61 treated samples and the increase in protective properties observed by EIS (Electrochemical Impedance Spectroscopy) in the immersion test in $0.6 \mathrm{M} \mathrm{NaCl}$. Heating for 5 to 60 minutes 
in air at $200^{\circ} \mathrm{C}$ seems to be an effective, easy to perform and inexpensive method for increasing the corrosion resistance of the AZ61 alloy by approximately two or three times.

Keywords: Magnesium alloys, Thermal treatments; Surface segregation; corrosion; X-ray photoelectron spectroscopy (XPS), 


\section{Introduction}

Chosen materials for this study are Mg-Al alloys, which have aroused great scientific and technological interest over the last two decades. From a practical point of view magnesium is the structural metal of lowest density, which makes it highly attractive for use in the automotive, aerospace, IT, and electronics industries where weight plays a decisive role. However, as magnesium is one of the most chemically active metals, insufficient resistance to atmospheric and aqueous corrosion sometimes limits its applications. Thus it is desirable to have as complete as possible information on the factors that influence the corrosion of these magnesium base materials. This work seeks to contribute to such information.

Many researchers have carried out studies to find relationships between changes in the alloy microstructure (amount and distribution of $\beta$-phase precipitates) with long term heat treatments ( $\mathrm{T} 4$ (solution treatment) or $\mathrm{T} 6$ (aging treatment)) [1-10] and changes in corrosion resistance. In the literature a great deal of attention has been paid to the role of the $\beta$-phase in the corrosion mechanism of magnesium/aluminium alloys. A generally accepted idea is that this phase acts as an effective cathode and/or barrier against corrosion, depending on its size and distribution [1].

In our previous studies [11-14], we have observed that the properties of the thin oxide/hydroxide native oxide surface film (only a few nanometres thick) may affect the corrosion properties of magnesium alloys in the atmosphere [11, 12] or in $\mathrm{NaCl}$ solution $[13,14]$. XPS analysis has revealed notable differences in the native oxide films formed in air on the surface of AZ31 and AZ61 alloys in as- 
received and freshly polished conditions. In the joint analysis of XPS and EIS data, attention has been drawn to the increase in the corrosion resistance value on the AZ61 alloy in freshly polished conditions, which showed a higher thickness and greater uniformity of the native oxide film. Following up the idea that the thin native oxide film may provide resistance to magnesium corrosion initiation and its propagation $[1,13,14]$, in the present research studies have been carried out into the possibility of improving its corrosion resistance by short heat treatments at $200^{\circ} \mathrm{C}$. As Jeurgens et al. noted [15], the thermal oxidation of metallic alloys at low temperatures (e.g. at $\mathrm{T}<600 \mathrm{~K}$ ) and for short times has only scarcely been investigated. The detailed chemical composition and constitution of the oxide films formed on such alloy surfaces at low temperatures for short heating times are unknown. Furthermore, there is no comprehensive knowledge of the effect of the concurrent processes of chemical segregation and preferential oxidation on both the developing oxide-film microstructure and the induced compositional changes in the alloy subsurface.

Czerwinski [16] studied the oxidation behaviour of AZ91D Mg alloy at different temperatures. His results showed that AZ91D exhibited protective oxidation only at a temperature of $197^{\circ} \mathrm{C}$, while at higher temperatures the behaviour was non-protective and associated with the formation of oxide nodules and their coalescence into a loose fine-grained structure. On the basis of these results, this study has selected a low-temperature heat treatment process at $200^{\circ} \mathrm{C}$ to study the possibility of improving the protective properties of the native oxide film formed on AZ31 and AZ61 Mg alloy surfaces. 
One of the main obstacles to characterise the thermally oxidised film formed on the surface of magnesium alloys after heating at low temperatures $\left(200^{\circ} \mathrm{C}\right)$ is its small thickness. As Czerwinski [16] reported, the maximum oxide thickness achieved during heating (as converted from weight gain data) was equal to 64 nanometres for $197^{\circ} \mathrm{C}$. This film thickness is too small to produce a sufficient signal for conventional materials characterisation techniques (Optical microscopy, SEM/EDX, XRD or TEM) [13]. The use of the XPS surface analysis technique makes it possible to reduce the analysed thickness to only $3 \mathrm{~nm}$ and supplies information on the oxidation state of the detected element.

The objectives of this research are as follows:

1. To study the chemical changes in the native oxide surface film of AZ31 and AZ61 alloys induced by short heat treatments at $200^{\circ} \mathrm{C}$ in order to try to find relationships between the chemistry of the thin oxide films, the nature of the alloy and the heating time.

2. To contribute to better understanding the effect of the chemistry and structure of the thin films (approximate thickness of 1-3 nanometers) formed on the surface of commercial Mg-Al alloys and their corrosion resistance in saline solutions. 


\section{Experimental}

The chemical compositions of the tested magnesium alloys, AZ31 and AZ61, are listed in Table 1. They were manufactured in wrought condition and supplied in $3 \mathrm{~mm}$ thick plates by Magnesium Elecktron Ltd. Freshly polished specimens were dry ground through successive grades of silicon carbide abrasive papers from P600 to P2000 followed by finishing with 3 and $1 \mu \mathrm{m}$ diamond paste, rinsed in water and dried with hot air. Due to the high affinity of magnesium to the ambient atmosphere, it was attempted to keep to a minimum (around $1 \mathrm{~h}$ ) the exposure time to the atmosphere prior to characterisation of the specimens.

The two alloys were oxidised in the same conditions in a thermogravimetric analyser (TGA) (TA instruments Q600 SDT) using cylindrical specimens of 4 $\mathrm{mm}$ in diameter by $2 \mathrm{~mm}$ in height (weighing approximately $44 \mathrm{mg}$ ). The apparatus was capable of accommodating a specimen with a maximum weight of $0.5 \mathrm{~g}$ and had a measurement accuracy of $0.1 \mu \mathrm{g}$. The reaction temperature was monitored by a Pt/Pt-Rh thermocouple. Weight change kinetics were measured in air under isothermal conditions at a temperature of $200^{\circ} \mathrm{C}$. The heating rate before reaching the isothermal condition was $50^{\circ} \mathrm{C} / \mathrm{min}$.

The simple thermal treatment consisted of horizontal exposure of $2 \mathrm{~cm} \times 2 \mathrm{~cm}$ square specimens of $A Z 31$ and $A Z 61$ alloys in a convective stove at $200^{\circ} \mathrm{C}$ in air for 5,20 , and 60 minutes.

XPS analysis of the samples was performed using a Thermo Scientific K-Alpha ESCA instrument equipped with aluminium $\mathrm{K}_{\alpha 1,2}$ monochromatized radiation at $1486.6 \mathrm{eV}$ X-ray source. The system is fitted with a charge compensation dual- 
beam source to minimize surface charging. Photoelectrons were collected from a take-off angle of $90^{\circ}$ relative to the sample surface. The measurement was performed in a constant analyser energy mode with a $100 \mathrm{eV}$ pass energy for survey spectra and $20 \mathrm{eV}$ pass energy for high-resolution spectra. Composition-depth profiling was performed by sequential XPS surface analysis and sputter etching using $3 \mathrm{keV}$ argon ion flux. Our previous results [13] on AZ31 and AZ61 alloys in polished condition, where we observed a sputtering rate of $5 \AA / m$ in, leads us to believe that this is approximately the rate which is obtained on specimens with the bombardment conditions and spectrometer used in this study. Survey scans and detailed scans of Mg 2p, Al 2s, C 1s and O 1s photoelectron emissions were recorded for each sample. The intensities were estimated by calculating the area under each peak after smoothing and subtraction of the S-shaped background and fitting the experimental curve to a combination of Lorentzian and Gaussian lines of variable proportions. Binding energies (BEs) were referenced to the adventitious C1s peak at $285.0 \mathrm{eV}$. The atomic ratios were computed from the peak intensity ratios and the reported atomic sensitivity factors [17]. The sampled areas were $1 \times 1 \mathrm{~mm}^{2}$.

Electrochemical impedance measurements were conducted with the specimens immersed in $0.6 \mathrm{M} \mathrm{NaCl}$ after 1 hour, 1 day, 7, 14, 21 and 28 days of exposure at room temperature $\left(25^{\circ} \mathrm{C}\right)$. An AUTOLAB potentiostat, model PGSTAT30, with frequency response analyser (FRA) software was used. The frequency ranged from $100 \mathrm{kHz}$ to $1 \mathrm{mHz}$ with 5 points/decade, whereas the amplitude of the sinusoidal potential signal was $10 \mathrm{mV}$ with respect to the open circuit potential. A typical three-electrode setup was employed: $\mathrm{Ag} / \mathrm{AgCl}$ and graphite were used 
as reference and counter electrodes, respectively, and the material under study was the working electrode.

For the hydrogen evolution determinations, the corrosion of magnesium alloys during solution immersion was estimated by determining the volume of hydrogen evolved during the corrosion process. Samples for hydrogen collection were cut into square coupons with dimensions of $2 \times 2 \times 0.3 \mathrm{~cm}$ and vertically immersed in $700 \mathrm{ml}$ of quiescent $0.6 \mathrm{M} \mathrm{NaCl}$ for 14 days in a beaker open to laboratory air at $25 \pm 2{ }^{\circ} \mathrm{C}$. The entire specimen surface was exposed to the electrolyte. Evolved hydrogen was collected in a burette above an inverted funnel placed centrally above specimen. All these experiments were run simultaneously and each sample was subjected to essentially the same temperature and exposure history. The experimental difficulties and limitations of such test was recently documented [18]. For the gravimetric determination of corrosion, the specimens were weighed before exposure and then after testing were pickled in chromic acid to remove the corrosion products, rinsed with isopropyl alcohol, dried in hot air and reweighed in order to calculate the mass loss per unit of surface area. 


\section{Results}

\subsection{Thermogravimetric analysis}

Figure 1 compares the weight change kinetics curves obtained for alloys AZ31 and $A Z 61$ after heating at $200^{\circ} \mathrm{C}$ in an air environment. It is interesting to note that the mass change values are similar in the case of the two alloys (Fig. 1) and that some mass loss is observed during the first 35 minutes of exposure, followed by an approximately steady state region and then a slight increase in weight. Liu et al [19], studying the oxidation of pure $\mathrm{Mg}$ and $\mathrm{Mg}-\mathrm{Gd}-\mathrm{Y}-\mathrm{Zr}$ alloys at $300^{\circ} \mathrm{C}$, attributed the mass loss at the start of the mass change measurements due to dehydration and disintegration of the external $\operatorname{Mg}(\mathrm{OH})_{2}$ layer formed during mechanical polishing.

\subsection{Microstructural characterization}

Figure 2 compares the size and amount of the precipitates on the surface of the non-heated AZ31 and AZ61 alloys and heated for 60 minutes. The SEM micrographs obtained for other heat treatment times are fairly similar and are not shown. Throughout the work, in order to avoid repeating similar results (micrographs or XPS spectra), only those necessary to support the corresponding facts are displayed. A small amount of precipitates is observed for the non-heated AZ31 alloy (Fig. 2a) and AZ61 alloy (Fig. 2b). The backscattered electrons produce a sharp contrast between the bright particles and the magnesium-rich matrix. By comparing Fig. 2a with Fig. 2c for AZ31 alloy and Fig. $2 b$ with Fig. $2 d$ in the case of the AZ61 alloy, it is apparent that the size and amount of the precipitates on the surface do not change significantly with the treatment time. 
Fig. 3 shows elemental mapping results of the non-heated AZ31 alloy surface. Fig. 3a-3d respectively shows the surface morphology (backscattering electron imaging: $\mathrm{BEI}$ ) and elemental maps of $\mathrm{Al}, \mathrm{Mn}$ and $\mathrm{Fe}$. The elemental mapping results indicate that the bright particles contain $\mathrm{Al}$ and $\mathrm{Mn}$ (Figs. 3b and 3c). In contrast, it is interesting to note that no iron is detected on the particles or on the matrix (Fig. 3d).

Figure 4 compares the surface microstructures for the non-heated AZ31 and AZ61 magnesium alloys and heated for 60 minutes. The microstructure of the AZ31 alloy is formed practically by an a-matrix with Al in solid solution (Fig. 4a), while a large part of the Al in the microstructure of the AZ61 alloy is precipitated in the form of $\beta$-phase (Fig. 4b). As commented earlier for the Al-Mn precipitates, no significant differences in the grain morphology and size are observed in both alloys after 60 minutes of heat treatment (Figs $4 \mathrm{c}$ and $4 \mathrm{~d}$ ) compared with the non-heated alloy (Figures 4a and 4b).

\subsection{Changes in the chemistry of the surface films formed on AZ31 and AZ61} alloys with the heating treatment

Figure 5 shows the high resolution spectra for $\mathrm{C} 1$ s peak obtained on the nonsputtered surfaces of the AZ31 alloy: non-heated (a) and heated for 60 minutes (b) and of the AZ61 alloy: non-heated (c) and heated for 60 minutes (d), with those corresponding to the same surfaces after 2 minutes of sputtering (e-h), 5 minutes of sputtering (i-l) and 10 minutes of sputtering $(m-p)$. The spectra can be fitted using two components at different binding energies: at $285.0 \mathrm{eV}$, which may be associated with the presence of $\mathrm{C}-\mathrm{C} / \mathrm{C}-\mathrm{H}$ groups; and a less intense component about 4.5-5.0 eV higher which is associated with the presence of 
magnesium carbonate [20]. The first component, $\mathrm{C}-\mathrm{C} / \mathrm{C}-\mathrm{H}$ groups, appears on the outer surface ( $<3 \mathrm{~nm}$ in thickness) of almost any metal in contact with the atmosphere at room temperature, irrespective of its composition. Magnesium carbonate formation can be explained by the diffusion of $\mathrm{CO}_{2}$ from the environment and its reaction with the oxide film on the freshly polished surface [21]. After 2 minutes of sputtering, the intensity of the magnesium carbonate component observed on the surface of the AZ61 alloy (Fig. $5 \mathrm{~g}$ and 5h) was higher than on the AZ31 alloy (Fig. 5e and 5f). In a previous study [12] some correspondence was observed between the presence of $\beta$ phase $\left(\mathrm{Mg}_{17} \mathrm{Al}_{12}\right)$ and the amount of magnesium carbonate formed on the surface after atmospheric exposure. The results of this work tend to support this behaviour. From the point of view of magnesium alloy protection mechanisms, the formation of a carbonate product layer, thicker than that observed in this work, provides better passivation of the surfaces and retards chloride-induced corrosion in the passivation zone [22]. It is interesting to note that the magnesium carbonate content observed in the XPS analysis of the outer surface of the alloys (Fig. $5 \mathrm{a}-5 \mathrm{~h}$ ) tends to decline quickly with sputtering time (Fig. 5i-5p), probably because its presence is limited to the outermost surface of the magnesium specimen.

Figure 6 compares the high resolution spectra for Al2s peak obtained on the non-sputtered surfaces of the AZ31 alloy: non-heated (a) and heated for 60 minutes (b) and of the AZ61 alloy: non-heated (c) and heated for 60 minutes (d), with those corresponding to the same surfaces after 2 minutes of sputtering (e-h), 5 minutes of sputtering (i-l) and 10 minutes of sputtering (m-p). No appreciable aluminium signal is detected on the spectra obtained on the non- 
sputtered surfaces (Figs. 6a-6d). After 2 minutes of sputtering, the spectra obtained on the AZ31 alloy non-heated (Fig.6e) and heated for 60 minutes (Fig. 6f), as well as on the AZ61 alloy heated for 60 minutes (Fig. 6h), contain one single component at a binding energy of approximately $120.0 \mathrm{eV}$ associated with the presence of aluminium in the form of $\mathrm{Al}^{3+}$. The spectra obtained on the non-heated AZ61 alloy after 2 minutes of sputtering (Fig. 6g) show the most intense component at a binding energy of $118.0 \mathrm{eV}$, associated with the presence of metallic aluminium $\left(\mathrm{Al}^{0}\right)$, and a less intense component at a binding energy of $120.0 \mathrm{eV}$. After 5 minutes of sputtering (Figs. 6i-6l) the intensity of the metallic aluminium $\left(\mathrm{Al}^{0}\right)$ signal tends to rise and the intensity of the aluminium oxide $\left(\mathrm{Al}^{3+}\right)$ signal tends to decline quickly. No appreciable changes in the shape of the spectra have been observed after 10 minutes of sputtering between the non-heated alloys (Figs. $6 \mathrm{~m}$ and 60 ) and heated for 60 minutes (Figs. $6 n$ and $6 p$ ). Attention is drawn to the significant increase in the metallic to oxide height (intensity) ratio in the Al2s peak obtained on the AZ61 alloy surface after 5 (Figs. 6k and 6l) or 10 minutes of sputtering (Figs. 6o and 6p) compared to that corresponding to the AZ31 alloy (Figs. 6i, 6j, 6m and 6n). This difference in trend suggests that a large part of the Al is in metallic state in solid solution in the AZ61 alloy, and as aluminium oxide particulates in the layers close to the outermost surface in the case of the AZ31 alloy [13].

Figure 7 compares the evolution with sputtering time of the high resolution spectra Mg2p peak obtained on the AZ31 alloy surface non-heated (a, e, i, m) and heated for 60 minutes $(b, f, j, n)$ with those obtained on the AZ61 alloy surface non-heated (c, g, k, o) and heated for 60 minutes $(\mathrm{d}, \mathrm{h}, \mathrm{I}, \mathrm{p})$. The spectra obtained on the non-sputtered surface (Figs. 7a-7d) contain one single 
component at a binding energy of $50.8 \mathrm{eV}$ associated with the presence of magnesium in the form of magnesium hydroxide/carbonate [20]. After 2 minutes of sputtering, a higher intensity second component appears at a binding energy of $49.7 \mathrm{eV}$, associated with the presence of magnesium in metallic state on the surface of the non-heated AZ31 and AZ61 alloys (Figs. 7e and 7g). Attention is drawn to the different shape of the spectra obtained on alloys AZ31 or AZ61 heated for 60 minutes after 2 min of sputtering (Figs $7 f$ and 7 h, respectively), with a higher intensity of the $\mathrm{Mg}^{2+}$ component respect to the $\mathrm{Mg}^{0}$ component which could be explained by the formation of a thicker magnesium oxide layer after the heat treatment. After 5 minutes of sputtering, the intensity of the $\mathrm{Mg}^{0}$ component observed in the heated samples (Figs $7 \mathrm{j}$ and $7 \mathrm{l}$ ) increased significantly and no differences are observed in the $\mathrm{Mg}^{2+}$ to $\mathrm{Mg}^{0}$ component height (intensity) ratio in the Mg2p peak compared to the non heated samples (Figs. $7 \mathrm{i}$ and $7 \mathrm{k}$ ). No appreciable changes between the samples non-heated and heated for 60 minutes have been observed in the shape of the spectra after 10 minutes of sputtering (Figs. $7 \mathrm{~m}-7 \mathrm{p}$ ). The fact that $\mathrm{Al}^{3+}$ and $\mathrm{Mg}^{2+}$ signals do not cease to be present on the surface of the specimens after long sputtering times (Figs. 6i-6p and 7i-7p) may be due to the presence of residues of $\mathrm{Al}_{2} \mathrm{O}_{3}$ and $\mathrm{MgO}$ that cannot be removed by the incident argon ions.

Figure 8 compares the variation in the $\mathrm{Al}^{0} /\left(\mathrm{Al}^{0}+\mathrm{Mg}^{0}\right) \times 100$ atomic ratio obtained by XPS on the AZ31 and AZ61 alloy surfaces as a function of heating and sputtering times. This ratio was calculated from the area of the $\mathrm{Al}^{0}$ and $\mathrm{Mg}^{0}$ components in the fitting of the Al2s (Fig. 6) and Mg2p (Fig. 7) spectra and the atomic percentages of $\mathrm{Al}$ and $\mathrm{Mg}$ obtained by XPS on the surface of the alloys 
(not shown). It is interesting to note that the fraction of area occupied by the intermetallic precipitate of $\beta$ - phase in the grain boundaries of alloy AZ61 is very small (Figs. 4b and 4d). Thus, the XPS results (which refer to an analysis area of $1 \mathrm{~mm} \times 1 \mathrm{~mm}$ ) give an average surface chemistry which is dominated to a large extent by the effect of the a-phase.

Strong Al enrichment develops in the alloy subsurface region upon sputtercleaning, as experimentally confirmed in Ref. [15] . However, the fact that the $\mathrm{Al} /\left(\mathrm{Al}{ }^{0}+\mathrm{Mg}^{0}\right) \times 100$ atomic ratio obtained by XPS on the non-heated $\mathrm{AZ31}$ and AZ61 alloy surfaces are practically identical to that of the aluminium content in the bulk of these materials (Table 1) and remain approximately stable during the 10 minutes of sputtering (Fig. 8) suggest that this is not the origin of the phenomenon observed in our study.

\subsection{Electrochemical measurements}

\subsubsection{Charge transfer resistance measurements or corrosion rate.}

\subsubsection{Electrochemical impedance measurements}

The evolution of the corrosion process on the heat-treated AZ31 and AZ61 alloys immersed in $0.6 \mathrm{M} \mathrm{NaCl}$ solution has been monitored by means of impedance measurements. The Nyquist diagrams (Fig. 9) show the presence of a capacitive loop at high frequencies $(\mathrm{HF})$ and an inductive loop at low frequencies (LF). In the literature about the corrosion of magnesium alloys is normal to associate the diameter of the capacitive loop in the HF frequency region with the charge transfer resistance $\left(R_{C T}\right)$ of the corrosion process [23$25]$, value which is inversely related to the corrosion current ( $\left.i_{\text {corr }}\right)$ through the well known Stern-Geary equation [26]. In a previous investigation [13], an 
empirical determination of the proportionality constant B from the correlation between electrochemical and gravimetric measurements yielded values of around $65 \mathrm{mV}$ for the AZ31 alloy and of around $120 \mathrm{mV}$ for the AZ61 alloy.

Figure 10 shows the evolution of the charge transfer resistance $\left(R_{C T}\right)$ deduced from the capacitive loop at high frequencies (HF) with immersion time in $0.6 \mathrm{M}$ $\mathrm{NaCl}$ solution.

$R_{C T}$ data together with Stern-Geary equation have enabled electrochemical calculations of corrosion rate and amount of corroded metal. For determination of the amount of corroded metal over an extended period of time, $\mathrm{i}_{\text {corr }}$ values have been converted into weight losses by applying Faraday's law and integrating the weight changes for individual exposure periods over the considered interval. This way, the results depicted in Fig. 11 were determined, which show the instantaneous corrosion rate variations with time over 28 days immersion. On the other hand, Fig. 12 shows the average corrosion rates of the specimens after 14 days of exposure to the $0.6 \mathrm{M} \mathrm{NaCl}$ solution.

\subsubsection{Hydrogen evolution measurements}

Fig. 13 is instructive in showing the differences in the hydrogen volume data between heat treated AZ31 and AZ61 alloys over 14 days of immersion in $0.6 \mathrm{M}$ $\mathrm{NaCl}$. It is interesting to note that similar trends regarding the corrosion behaviour are deduced from these hydrogen evolution determinations that from the electrochemical ones.

Fig. 12, which compares the amounts of corroded metal determined by hydrogen evolution, gravimetric and electrochemical measurements, also gives 
us an idea of the degree of similarity between these three types of determinations.

\section{Discussion}

4.1. Changes in chemical composition of the thin oxide films grown on AZ31 and AZ61 alloys by themal oxidation at $200^{\circ} \mathrm{C}$

As can be seen in figure 1 , the time interval of $35-60$ minutes of heating at $200^{\circ} \mathrm{C}$ was characterised by a very small weight gain, around only $0.6 \mu \mathrm{g} / \mathrm{cm}^{2}$, similar for the two alloys, which corresponds approximately to an oxide film thickness of $17 \AA$. This data is consistent with the small increase in the thickness of the MgO film on the surface of the alloys as seen by XPS after 60 minutes of heating and commented above. It is generally accepted that the growth of compact $\mathrm{MgO}$ films is controlled by solid sate diffusion through adherent oxide areas followed by the reaction with oxygen at the oxide/gas interface. Hence, a lack of easy-paths for fast $\mathrm{Mg}$ transport could be a possible explanation of highly protective behaviour [16]. Since the diffusivity of Mg within the $\mathrm{MgO}$ lattice is expressed by [27]:

$D_{\mathrm{L}}=1.0 \times 10^{-6} \exp (-150000 / R T) \mathrm{m}^{2} / \mathrm{s}$

at $473 \mathrm{~K}$ the value of $D$ is as low as $2.67 \times 10^{-23} \mathrm{~m}^{2} / \mathrm{s}$ justifying negligible weight. Similarly, in previous work [13] with the same alloys in $0.6 \mathrm{M} \mathrm{NaCl}$ solution, we observed that the homogeneous and continuous native oxide film formed on freshly polished samples had a possible inhibiting effect on the diffusion of magnesium atoms during the corrosion process. 
In general, the XPS analyses of the AZ61 heated samples show an important aluminium enrichment, mainly as metallic aluminium, at the interface between the surface oxide and the bulk of the alloy compared to the Al content on the non-heated alloy or in the bulk alloy (Fig. 8b). The relative $\mathrm{Al}^{0} /\left(\mathrm{Al}^{0}+\mathrm{Mg}^{0}\right) \times 100$ atomic ratio determined by XPS for the heated samples is 2-3 times higher than for the Al alloying bulk content or non-heated AZ61 alloys. This behaviour suggests the possibility of a considerably higher diffusion rate of $\mathrm{Al}$ than the $\mathrm{Mg}$ throughout the heat treatment. This idea could be sustained if the diffusivity values for $\mathrm{Al}$ in $\mathrm{MgO}$ are much higher than those corresponding to the diffusion of Mg. Recent data in the literature [28, 29] suggest diffusion coefficients for Al about ten orders of magnitude higher than for $\mathrm{Mg}$, which tends to support this possibility.

\subsection{Relationship between the chemistry of thin oxide films grown on the surface of magnesium alloys by themal oxidation and their corrosion resistance in saline solutions}

It seems likely that some differences revealed in the composition characteristics of oxide films formed on alloy AZ31 and AZ61 surfaces after the heat treatment may have an impact on the corrosion behaviour of the specimens in saline solutions. In this respect, attention is drawn to: (a) very thin MgO layer, only few nanometers thick, grown on the surface of polished commercial AZ31 and AZ61 alloys with the heat treatment conditions used in this study and (b) metallic Al enrichment in the subsurface layers of the thermally treated AZ61 alloy.

As pointed out in early studies by Pilling and Bedworth [30], due to the large difference in densities between the oxide and metal, expressed by the $\mathrm{MgO}$ to 
Mg volume ratio of 0.81 , oxide scale should not form a compact layer. Justified by our gravimetric and XPS results it may be inferred that a minimal formation of magnesium oxide occurs during the heating treatment. In a previous study [13] it was seen that the freshly polished AZ61 and AZ31 alloys showed better corrosion resistance than the alloys in as-received condition, probably due to the formation of a homogeneous, uniform passive thin layer on the polished surface. It is interesting to note that heating at $200^{\circ} \mathrm{C}$ avoids the adverse effect of the growth of thick $\mathrm{MgO}$ oxide layers at higher temperatures which may break the compact structure of the initial native oxide film impairing their diffusion barrier properties in a $\mathrm{NaCl}$ aqueous environment.

Jeurgens et al. [15] have investigated the growth kinetics and the evolution of the chemical composition and constitution of the initial oxide film grown on Mgbased MgAl surfaces by dry thermal oxidation, and observed that within the grown oxide films adjacent to the alloy/oxide interface the interstitial sites were preferentially occupied by Al cations. In the present study, attention is drawn to the preferential increase in the metallic component compared to the oxide component in the Al signal in the subsurface layer as a result of the heat treatment. It is speculated that the homogeneous, uniform and compact native oxide layer present on the surface of the alloys inhibits significantly the oxidation or solid state diffusion of the Al alloying element within the exposure times and temperature chosen in our study reducing the adverse effects on the protective properties associated to the growth of $\mathrm{Al}_{2} \mathrm{O}_{3}$ or $\mathrm{MgAl}_{2} \mathrm{O}_{4}$ type species [13].

In addition to the uniformity and compactness effects, the chemical composition of the thin oxide layers on surface of the AZ61 alloy after the thermal treatment 
also plays a fundamental part in the observed corrosion rate. Figures.10b, 11b, $12 \mathrm{~b}$ and $13 \mathrm{~b}$ reveal that metallic aluminium enrichment of the subsurface layers with heat treatment exerts an important effect in the evolution of $R_{C T}$ and corrosion values for the AZ61 alloy during the first 14 days of the immersion test in solution of $\mathrm{NaCl} 0.6 \mathrm{M}$. The findings of the present work suggest that the higher the amount of aluminium in the subsurface of the heated alloy better is corrosion resistance in saline solution. Many studies mention the beneficial effect of $\mathrm{Al}[11,31-36]$, which may become the essential factor in determining the passivity of the surface, improving the resistance to local breakdown of the oxide and reducing the chance of chloride ions penetrating as far as the metal surface It is logical to relate a decrease in the corrosion rate with the strengthening of the thin magnesium oxide film spontaneously formed on the metallic surface of magnesium alloys by the Al enrichment induced by the heat treatment. Any increase in the percentage of passivating points or aluminium hydroxide areas on the metallic surface will reduce the tendency (stimulated by the presence of $\mathrm{Cl}$-ions) for metallic ions to pass from the reactive bare surface into the aqueous solution.

Finally, in the case of the AZ31 specimens, it is interesting to note the absence of significant variations in the corrosion rate, (Figs.11a and 12a) or in the volumes of hydrogen evolved (Fig. 13a) as a function of the heating time, where the XPS analyses (Figs.8a) has revealed Al contents on the heated specimens similar to those observed on the non-heated alloy or in the bulk alloy (Table 1). This fact tends to support the idea that the aluminium incorporation in the 
magnesium oxide film that covers the surface of the magnesium alloys after the heat treatment plays a fundamental part in the observed corrosion rate.

\section{Conclusions}

XPS analysis has been used to characterise the subtle changes in the chemical composition of native films formed in air on the surface of AZ31 and AZ61 alloys as a result of heating at a temperature of $200^{\circ} \mathrm{C}$ for a time of between 5 minutes and 1 hour. Attention is drawn to the metallic aluminium enrichment on the subsurface layers of the AZ61. Close to two or three times higher metallic aluminium contents have been found in these layers compared to the bulk content.

The native oxide film formed on the surface of polished AZ31 and AZ61 alloys seems to significantly inhibit the growth of magnesium oxide- or $\mathrm{Al}^{3+}$ enriched surface layers during thermal treatment in air at $200^{\circ} \mathrm{C}$ and periods of 60 minutes.

Charge transfer values $\left(R_{C T}\right)$, obtained from EIS measurements in an interval between $1 \mathrm{~h}$ and 28 days of immersion in $0.6 \mathrm{M} \mathrm{NaCl}$ solution, have allowed the establishment of relationships between the chemical composition of the thin surface films formed as a result of the heating treatment and the corrosion resistance of the alloys. There is a notable rise in the $R_{C T}$ values of the AZ61 alloy in $\mathrm{NaCl}$ as a result of the prior heating process, even for the earliest stages (only 5 minutes). This effect is less evident in the AZ31 alloy.

Combined analysis of XPS and EIS data suggests a favourable effect for corrosion resistance of: a) metallic Al enrichment in the subsurface of the 
thermally treated alloy; and b) the absence of significant changes in the uniformity, homogeneity and compactness of the native oxide film formed on the surface of polished commercial AZ31 and AZ61 alloys during thermal oxidation of the alloys at $200^{\circ} \mathrm{C}$ in air.

\section{Acknowledgments}

The authors express their gratitude to Prof. S. Feliu for several clarifying and stimulating discussions during the course of this work. They also gratefully acknowledge financial support for this work from the Ministry of Economy and Competitivity of Spain (MAT 2009-13530 and MAT2012-30854). 


\section{References}

[1] M.C. Zhao, M. Liu, G.L. Song, A. Atrens, Influence of the beta-phase morphology on the corrosion of the Mg alloy AZ91, Corros. Sci. 50 (2008) 19391953.

[2] M.C. Zhao, M. Liu, G.L. Song, A. Atrens, Influence of homogenization annealing of AZ91 on mechanical properties and corrosion behavior, Adv. Eng. Mater. 10 (2008) 93-103.

[3] C.L. Liu, Y.C. Xin, G.Y. Tang, P.K. Chu, Influence of heat treatment on degradation behavior of bio-degradable die-cast AZ63 magnesium alloy in simulated body fluid, Mater. Sci. Eng., A 456 (2007) 350-357.

[4] T. Beldjoudi, C. Fiaud, L. Robbiola, Influence of homogenization and artificial aging heat-treatments on corrosion behavior of Mg-Al alloys, Corrosion 49 (1993) 738-745.

[5] G.L. Song, A.L. Bowles, D.H. StJohn, Corrosion resistance of aged die cast magnesium alloy AZ91D, Mater. Sci. Eng., A 366 (2004) 74-86.

[6] N.N. Aung, W. Zhou, Effect of heat treatment on corrosion and electrochemical behaviour of AZ91D magnesium alloy, J. Appl. Electrochem. 32 (2002) 1397-1401.

[7] J.D. Majumdar, U. Bhattacharyya, A. Biswas, I. Manna, Studies on thermal oxidation of Mg-alloy (AZ91) for improving corrosion and wear resistance, Surf. Coat. Technol. 202 (2008) 3638-3642. 
[8] W. Zhou, T. Shen, N.N. Aung, Effect of heat treatment on corrosion behaviour of magnesium alloy AZ91D in simulated body fluid, Corros. Sci. 52 (2010) 1035-1041.

[9] L.Q. Zhu, W.P. Li, D.D. Shan, Effects of low temperature thermal treatment on zinc and/or tin plated coatings of AZ91D magnesium alloy, Surf. Coat. Technol. 201 (2006) 2768-2775.

[10] H.Y. Hsiao, P. Chung, W.T. Tsai, Baking treatment effect on materials characteristics and electrochemical behavior of anodic film formed on AZ91D magnesium alloy, Corros. Sci. 49 (2007) 781-793.

[11] S. Feliu Jr., M.C. Merino, R. Arrabal, A.E. Coy, E. Matykina, XPS study of the effect of aluminium on the atmospheric corrosion of the AZ31 magnesium alloy, Surf. Interface Anal. 41 (2009) 143-150.

[12] S. Feliu Jr., A. Pardo, M.C. Merino, A.E. Coy, F. Viejo, R. Arrabal, Correlation between the surface chemistry and the atmospheric corrosion of AZ31, AZ80 and AZ91D magnesium alloys, Appl. Surf. Sci. 255 (2009) 41024108.

[13] S. Feliu Jr., C. Maffiotte, A. Samaniego, J.C. Galvan, V. Barranco, Effect of the chemistry and structure of the native oxide surface film on the corrosion properties of commercial AZ31 and AZ61 alloys, Appl. Surf. Sci. 257 (2011) 8558-8568.

[14] S. Feliu Jr., C. Maffiotte, A. Samaniego, J.C. Galvan, V. Barranco, Effect of naturally formed oxide films and other variables in the early stages of $\mathrm{Mg}$-alloy corrosion in NaCl solution, Electrochim. Acta 56 (2011) 4554-4565. 
[15] L.P.H. Jeurgens, M.S. Vinodh, E.J. Mittemeijer, Initial oxide-film growth on Mg-based MgAl alloys at room temperature, Acta Mater. 56 (2008) 4621-4634.

[16] F. Czerwinski, The oxidation behaviour of an AZ91D magnesium alloy at high temperatures, Acta Mater. 50 (2002) 2639-2654.

[17] C.D. Wagner, L.E. Davis, M.V. Zeller, J.A. Taylor, R.H. Raymond, L.H. Gale, Empirical atomic sensitivity factors for quantitative-analysis by electronspectroscopy for chemical-analysis, Surf. Interface Anal. 3 (1981) 211-225.

[18] N.T. Kirkland, N. Birbilis, M.P. Staiger, Assessing the corrosion of biodegradable magnesium implants: a critical review of current methodologies and their limitations, Acta Biomater. 8 (2012) 925-936.

[19] J.W. Liu, Y. Li, F.H. Wang, The High Temperature Oxidation Behavior of Mg-Gd-Y-Zr Alloy, Oxid. Met. 71 (2009) 319-334.

[20] H.B. Yao, Y. Li, A.T.S. Wee, An XPS investigation of the oxidation/corrosion of melt-spun Mg, Appl. Surf. Sci. 158 (2000) 112-119.

[21] M. Jönsson, D. Persson, D. Thierry, Corrosion product formation during $\mathrm{NaCl}$ induced atmospheric corrosion of magnesium alloy AZ91D, Corros. Sci. 49 (2007) 1540-1558.

[22] L. Wang, T. Shinohara, B.P. Zhang, XPS study of the surface chemistry on AZ31 and AZ91 magnesium alloys in dilute $\mathrm{NaCl}$ solution, Appl. Surf. Sci. 256 (2010) 5807-5812. 
[23] N. Pebere, C. Riera, F. Dabosi, Investigation of magnesium corrosion in aerated sodium-sulfate solution by electrochemical impedance spectroscopy, Electrochim. Acta 35 (1990) 555-561.

[24] G.L. Makar, J. Kruger, Corrosion studies of rapidly solidified magnesium alloys, J. Electrochem. Soc. 137 (1990) 414-421.

[25] S. Mathieu, C. Rapin, J. Hazan, P. Steinmetz, Corrosion behaviour of high pressure die-cast and semi-solid cast AZ91D alloys, Corros. Sci. 44 (2002) 2737-2756.

[26] M. Stern, A. L. Geary, Electrochemical polarization .1. A theoretical analysis of the shape of polarization curves J. Electrochem. Soc. 104 (1957) 5663.

[27] C. Lea, C. Molinari, Magnesium diffusion, surface segregation and oxidation in Al-Mg alloys, J. Mater. Sci. 19 (1984) 2336-2352.

[28] J.A. Van Orman, K.L. Crispin, Diffusion in oxides, Rev. Mineral. Geochem. $72(2010)$ 757-825.

[29] B.H. Zhang, X.P. Wu, Diffusion of aluminium in MgO: A thermodynamic approach study Chin. Phys. B 22 (2013) 056601.

[30] N.B. Pilling, R.E. Bedworth, The oxidation of metals at high temperatures, J. Inst. Met. 29 (1923) 529-582.

[31] R. Lindstrom, J.E. Svensson, L.G. Johansson, The influence of carbon dioxide on the atmospheric corrosion of some magnesium alloys in the presence of $\mathrm{NaCl}$, J. Electrochem. Soc. 149 (2002) B 103-107. 
[32] M. Liu, P.J. Uggowitzer, A.V. Nagasekhar, P. Schmutz, M. Easton, G. L. Song, A. Atrens, Calculated phase diagrams and the corrosion of die-cast Mg-Al alloys, Corros. Sci. 51 (2009) 602-619.

[33] J.H. Nordlien, K. Nisancioglu, S. Ono. N. Masuko, Morphology and structure of oxide films formed on MgAl alloys by exposure to air and water, J. Electrochem. Soc. 143 (1996) 2564-2572.

[34] A. Pardo, M.C. Merino, A.E. Coy, R. Arrabal, F. Viejo, E. Matykina, Corrosion behaviour of magnesium/aluminium alloys in $3.5 \mathrm{wt} . \% \mathrm{NaCl}$, Corros. Sci. 50 (2008) 823-834.

[35] M. Jönsson, D. Persson, R. Gubner, The initial steps of atmospheric corrosion on magnesium alloy AZ91D, J. Electrochem. Soc. 154 (2007) C 684691.

[36] N. Hara, Y. Kobayashi, D. Kagaya, N. Akao, Formation and breakdown of surface films on magnesium and its alloys in aqueous solutions, Corros. Sci. 49 (2007) 166-175. 


\section{Figure Captions}

Figure 1. Evolution of mass change values obtained in the polished AZ31 and AZ61 alloys as a function of the time of heating at $200^{\circ} \mathrm{C}$ in an air environment.

Figure 2. SEM micrographs (BSE mode) morphologies for AZ31 (a, c) and AZ61 magnesium alloys (b, d) non-heated ( $a, b)$ and heated for $60 \mathrm{~min}(\mathrm{c}, \mathrm{d})$, respectively.

Figure 3. SEM micrographs (BSE mode) morphologies for AZ31 (a, c) and AZ61 magnesium alloys (b, d) non-heated $(a, b)$ and heated for 60 min (c, d), respectively.

Figure 4. Microstructure for AZ31 (a, c) and AZ61 magnesium alloys (b, d) nonheated (a, b) and heated for 60 min (c, d), respectively.

Figure 5. Variation of the C1s high resolution peak obtained by XPS on the surface of the AZ31 and AZ61 alloys non-heated and heated for 60 minutes as a function of the time of sputtering.

Figure 6. Variation of the Al2s high resolution peak obtained by XPS on the surface of the AZ31 and AZ61 alloys non-heated and heated for 60 minutes as a function of the time of sputtering.

Figure 7. Variation of the Mg2p high resolution peak obtained by XPS on the surface of the AZ31 and AZ61 alloys non-heated and heated for 60 minutes as a function of the time of sputtering.

Figure 8. Variation in the $\mathrm{Al}^{0} /\left(\mathrm{Al}^{0}+\mathrm{Mg}^{0}\right) \times 100$ atomic ratio obtained by XPS on the surface of the AZ31 and AZ61 alloys as a function of the time of heating and time of sputtering. 
Figure 9. Variation in Nyquist plot for AZ31and AZ61 alloys with immersion time (hours or days on the $Y$-axis) and times of heating.

Figure 10. Variation in $R_{C T}$ values as a function of alloy type and of time of heating over 28 days immersion in $0.6 \mathrm{M} \mathrm{NaCl}$.

Figure 11. Variation in corrosion rates $(\mathrm{mm} / \mathrm{y})$ obtained from EIS as a function of the time of heating and alloy type over 28 days immersion in $0.6 \mathrm{M} \mathrm{NaCl}$.

Figure 12. Comparison of corrosion rates $(\mathrm{mm} / \mathrm{y})$ obtained from EIS with weight loss and hydrogen evolution measurements after 14 days immersion in $0.6 \mathrm{M}$ $\mathrm{NaCl}$.

Figure 13. Variation in $\mathrm{H}_{2}$ evolution volume values as a function of the time of heating and alloy type over 14 days immersion in $0.6 \mathrm{M} \mathrm{NaCl}$. 


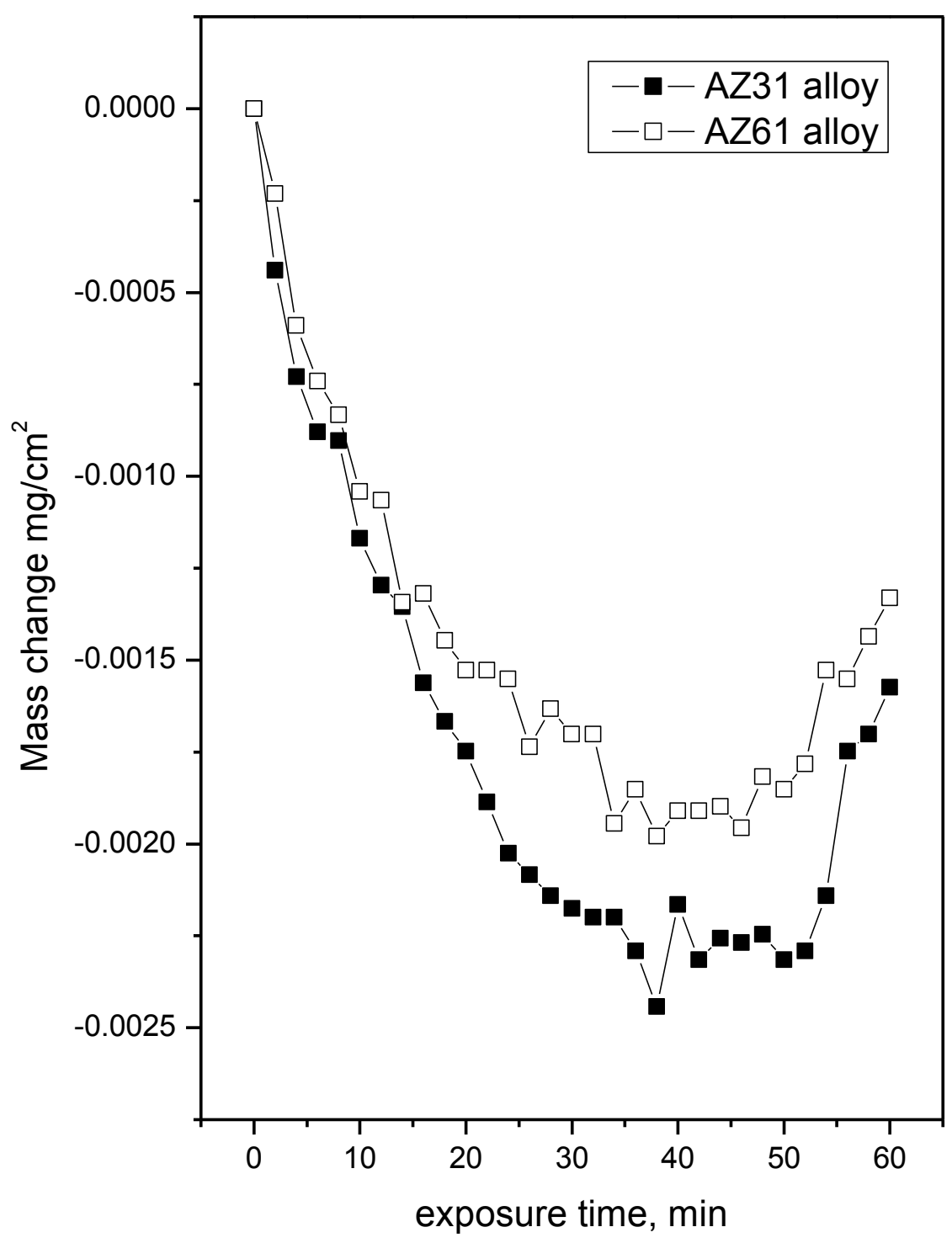

Figure 1. 
AZ31 alloy

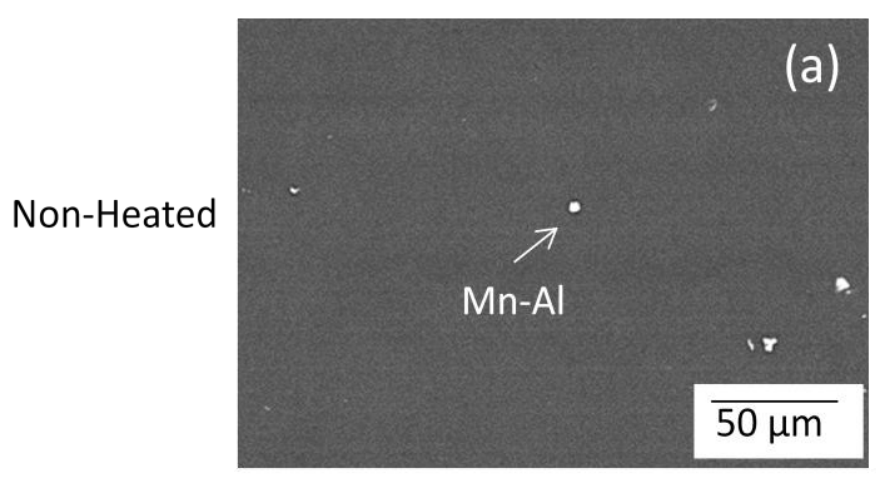

(c)

Heated

for

60 minutes

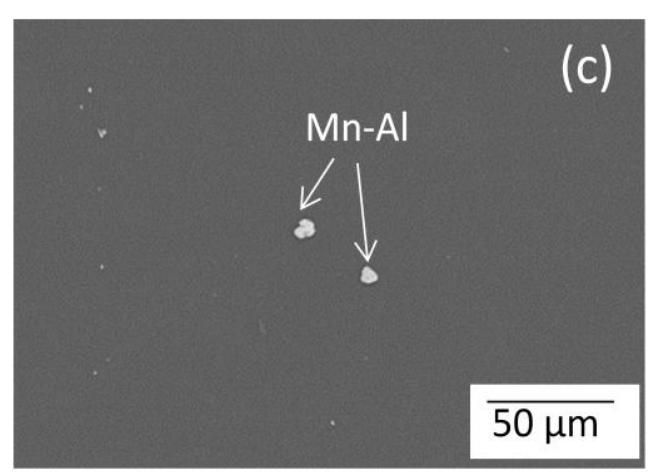

AZ61 alloy

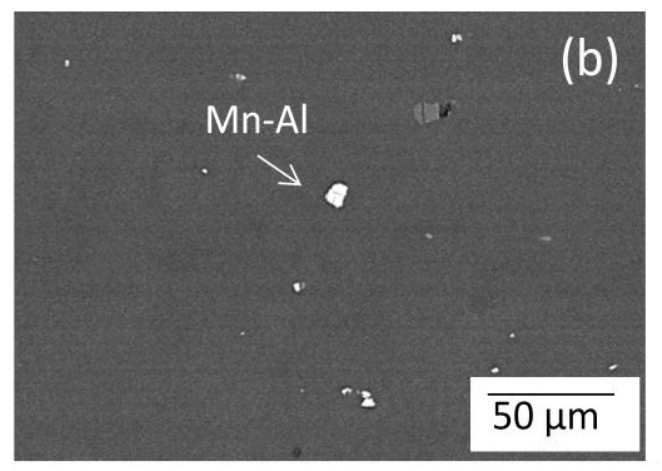

(d)

$\varepsilon_{s} \leftarrow M n-A I$

Figure 2. 
(a) $\mathrm{BEF}$

$$
\overline{50 \mu \mathrm{m}}
$$

(c) $\mathrm{Mn}$

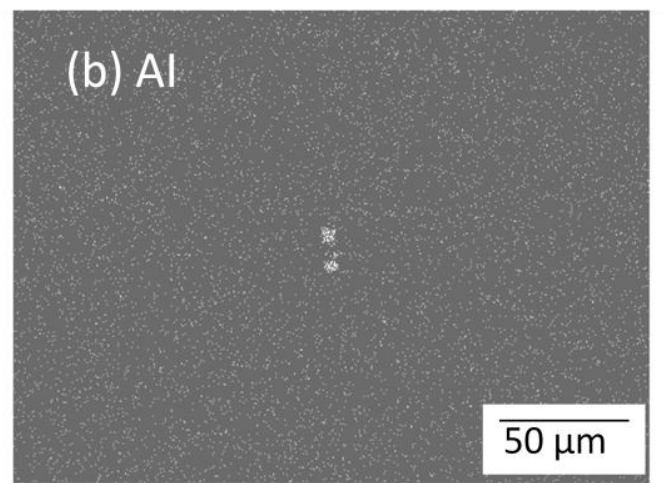

(d) Fe

Figure 3 
AZ31 alloy

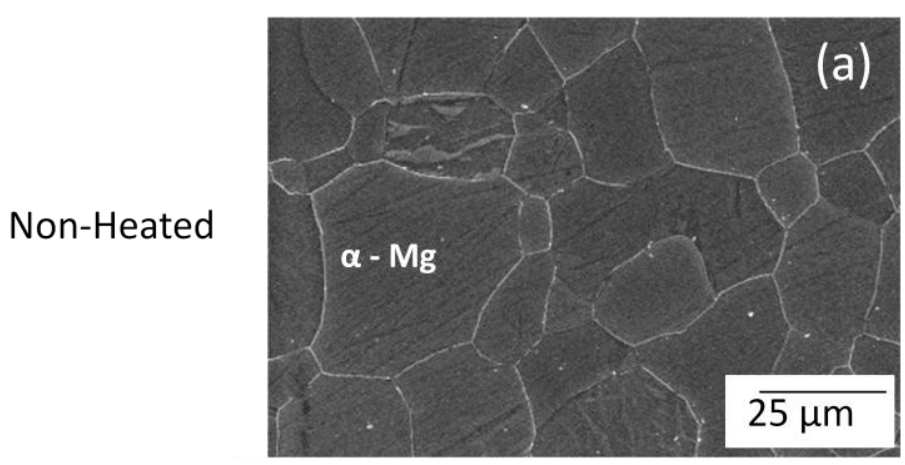

(a)

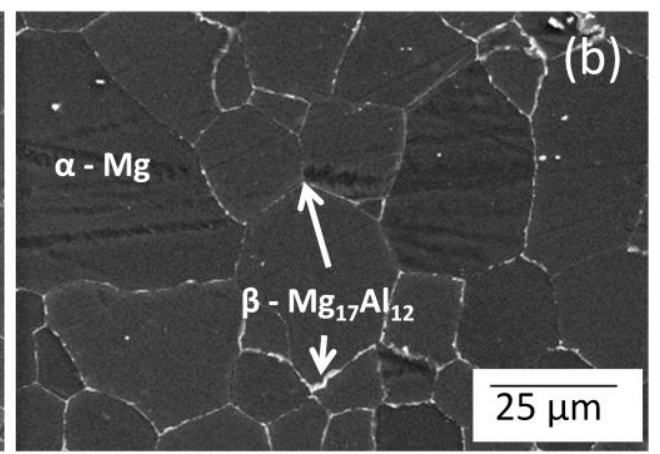

(c)

Heated

for

60 minutes
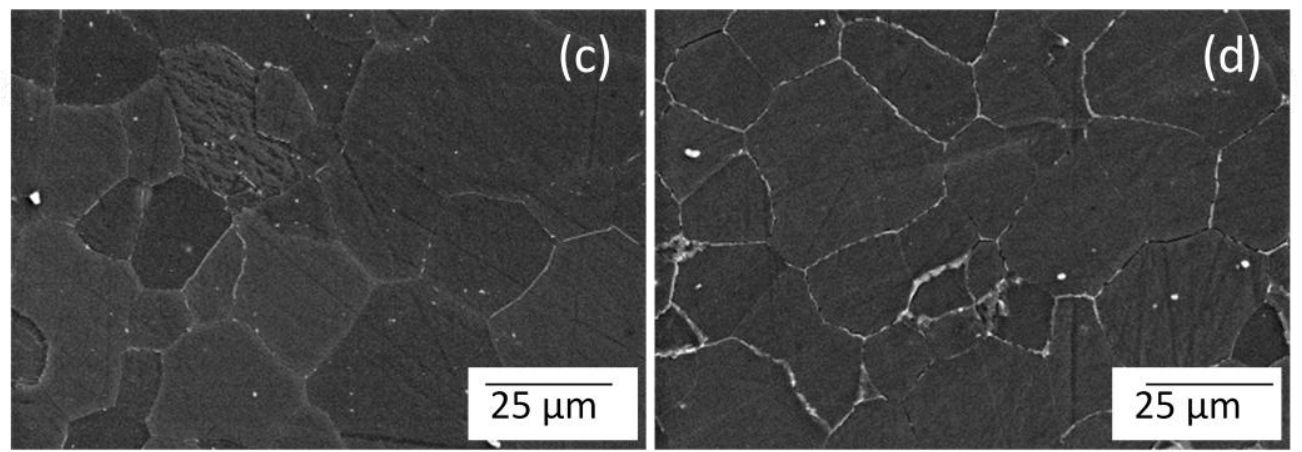

Figure 4. 


\section{1S peak}

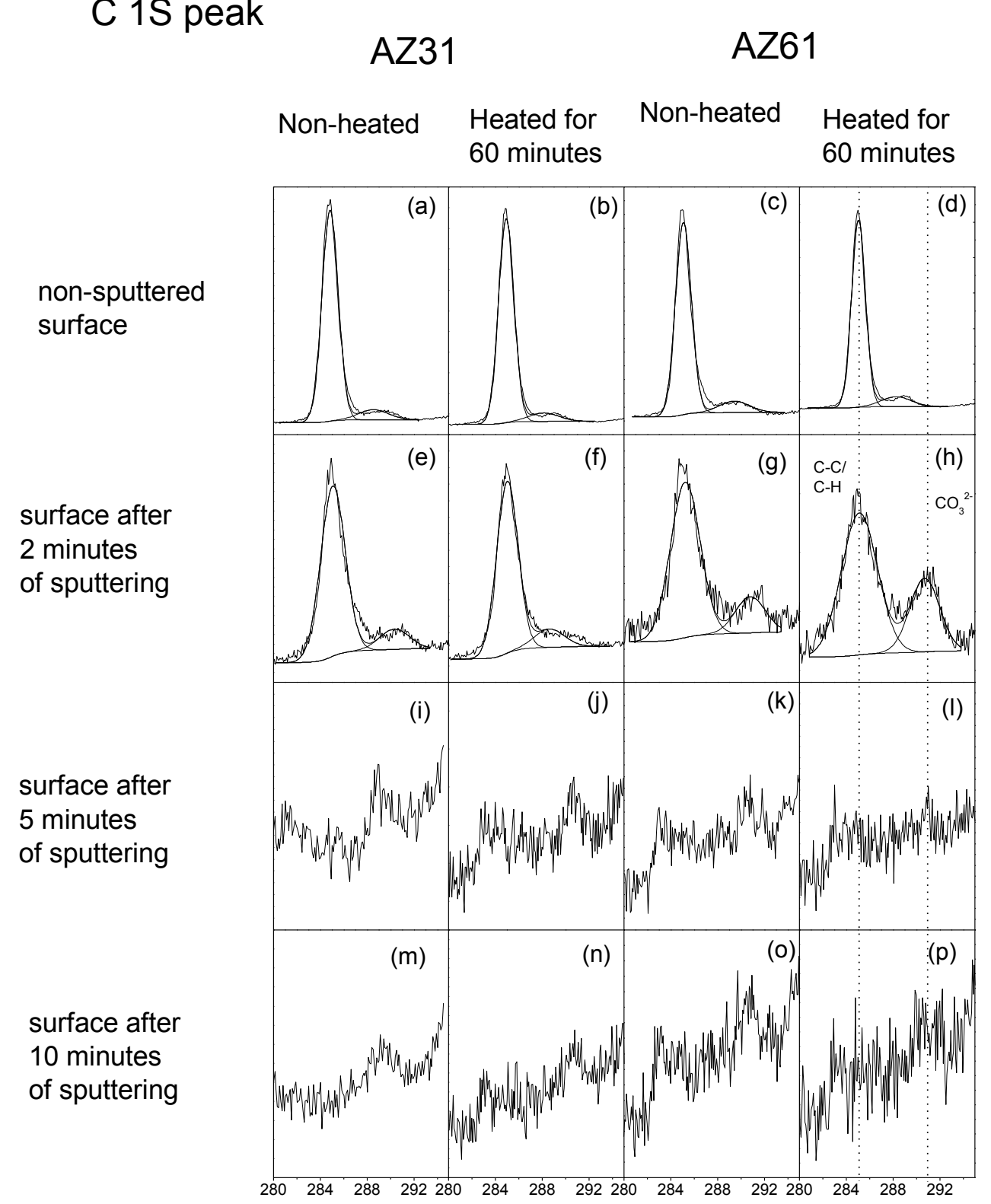

Binding energy / eV

Figure 5. 
Al 2s peak

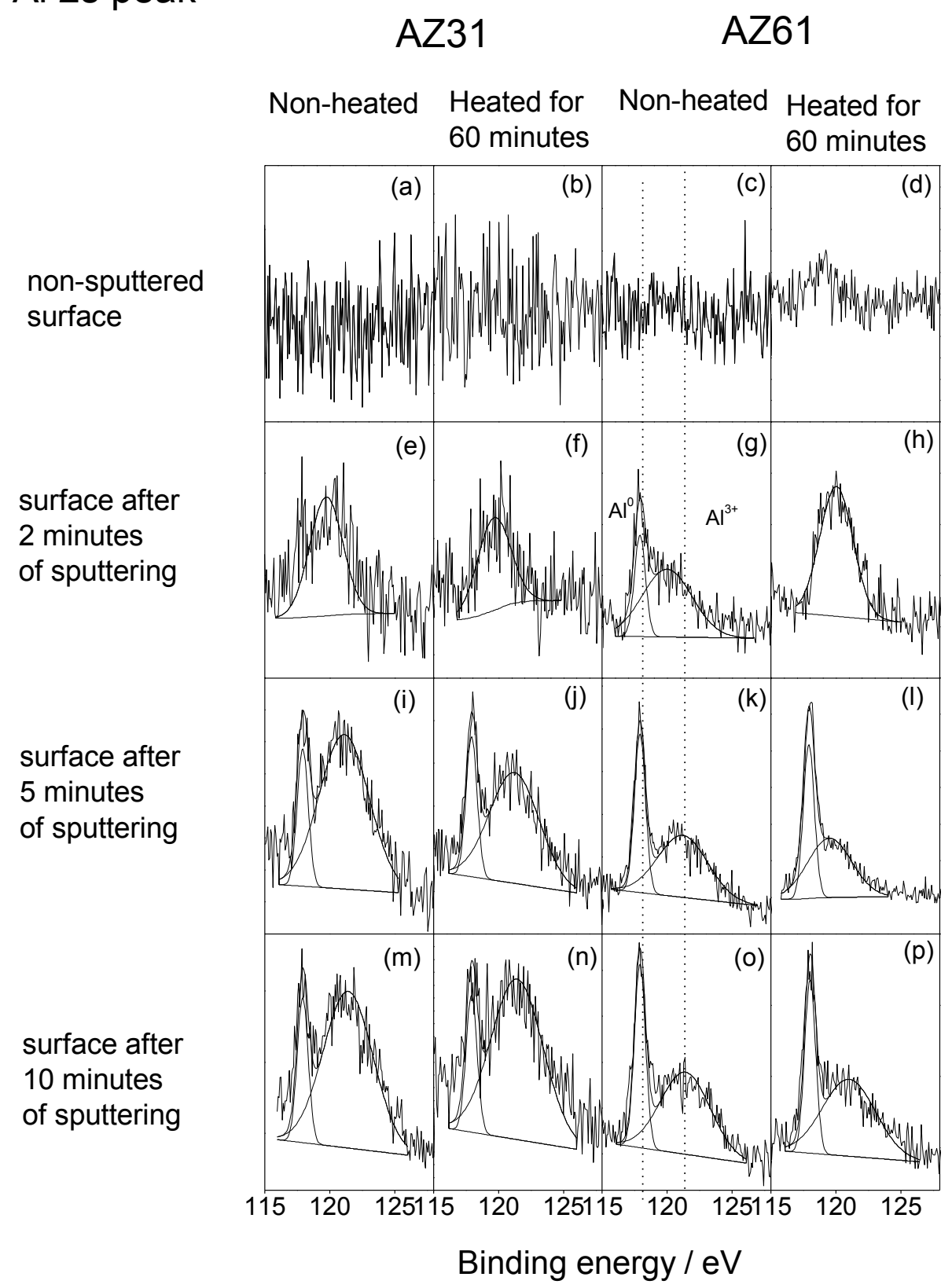

Figure 6 . 
Mg 2p peak

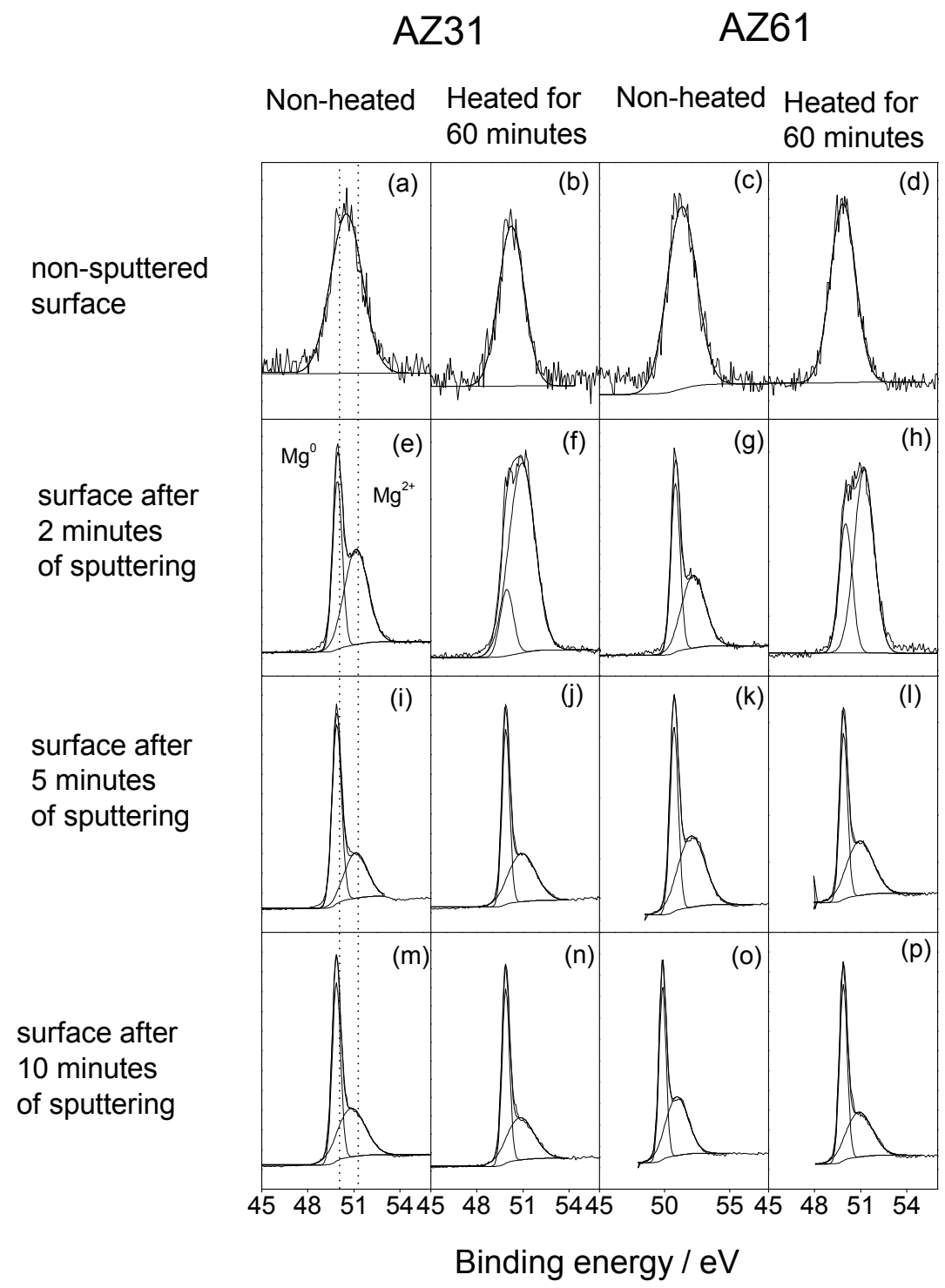

Figure 7. 


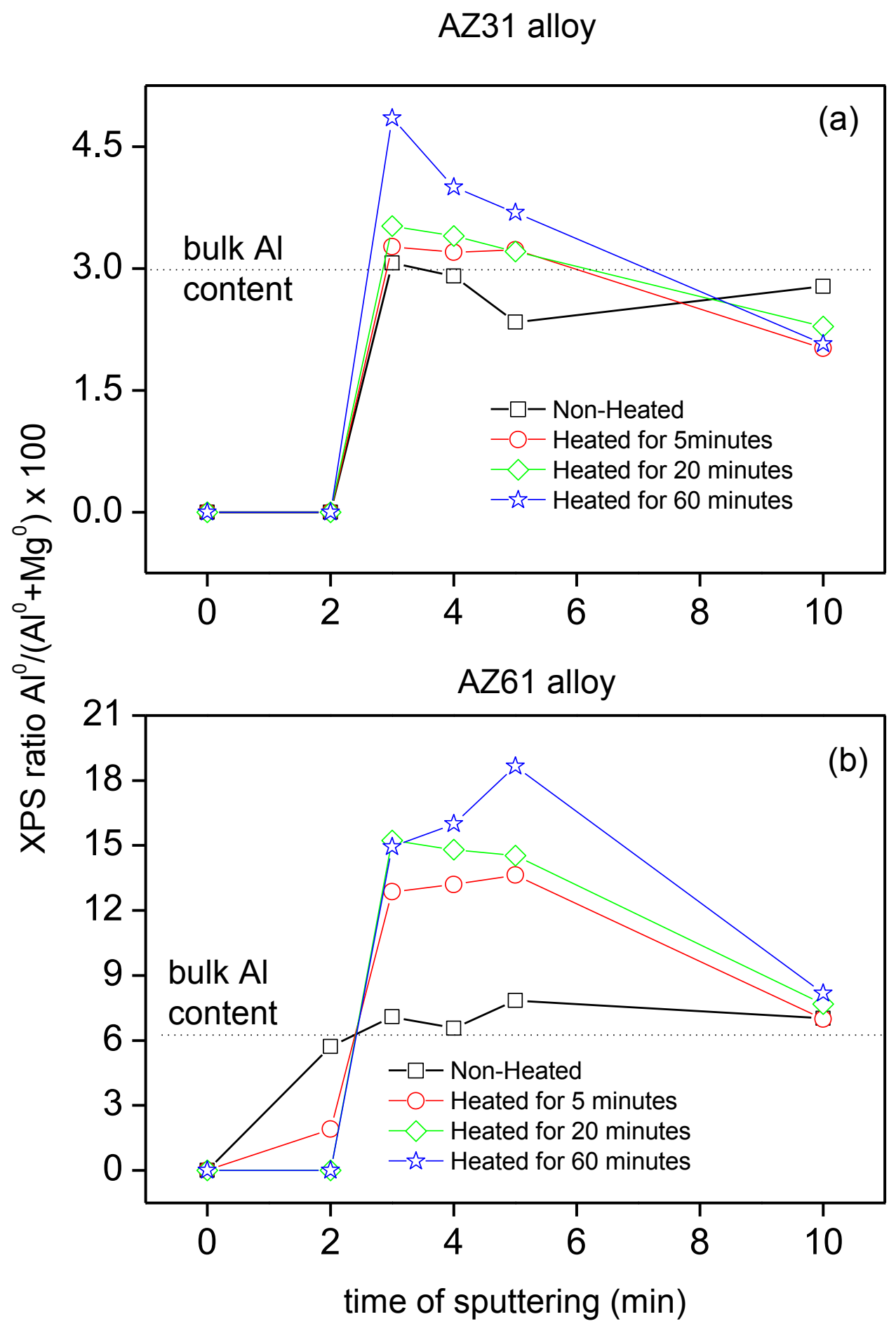

Figure 8. 

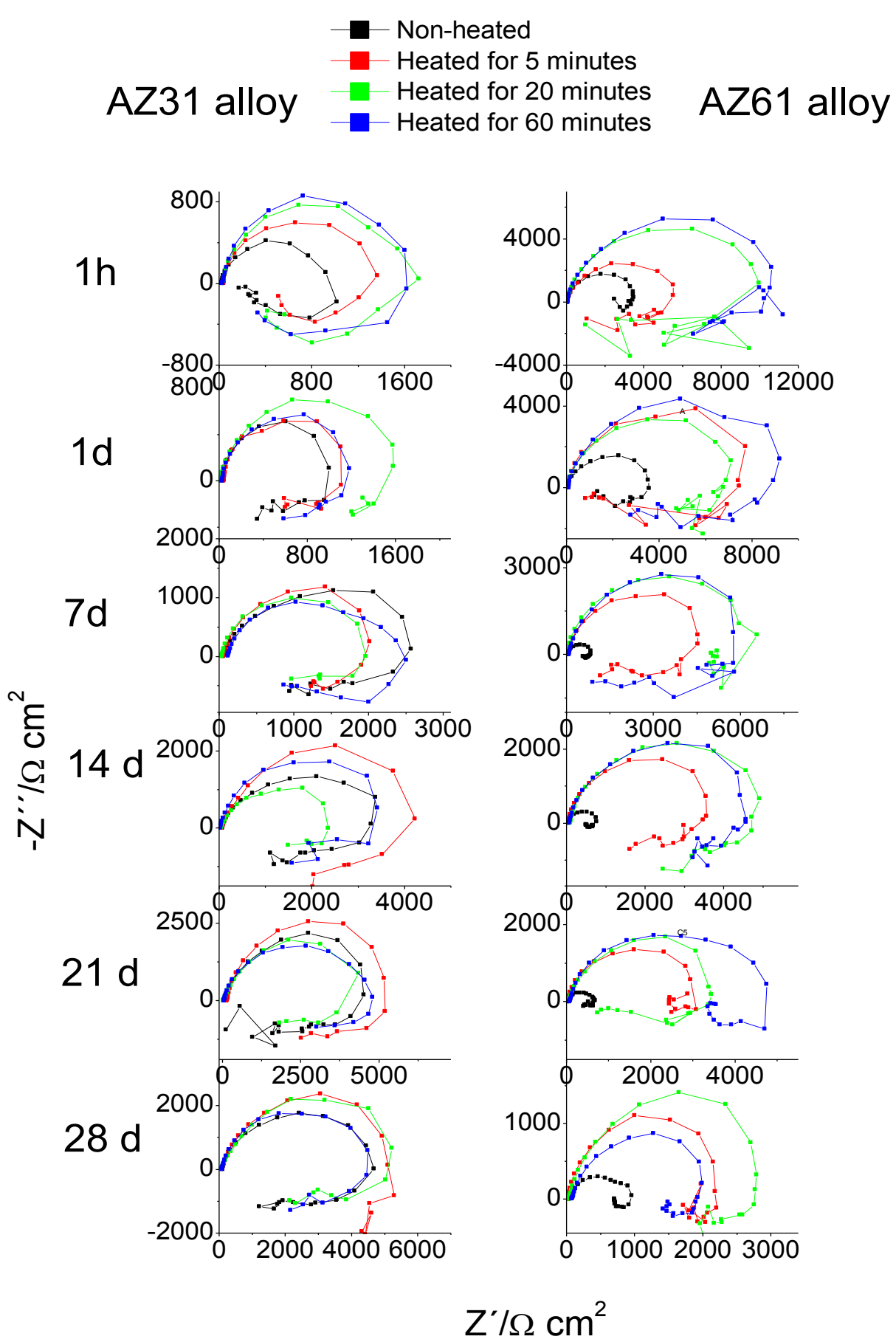

Figure 9. 


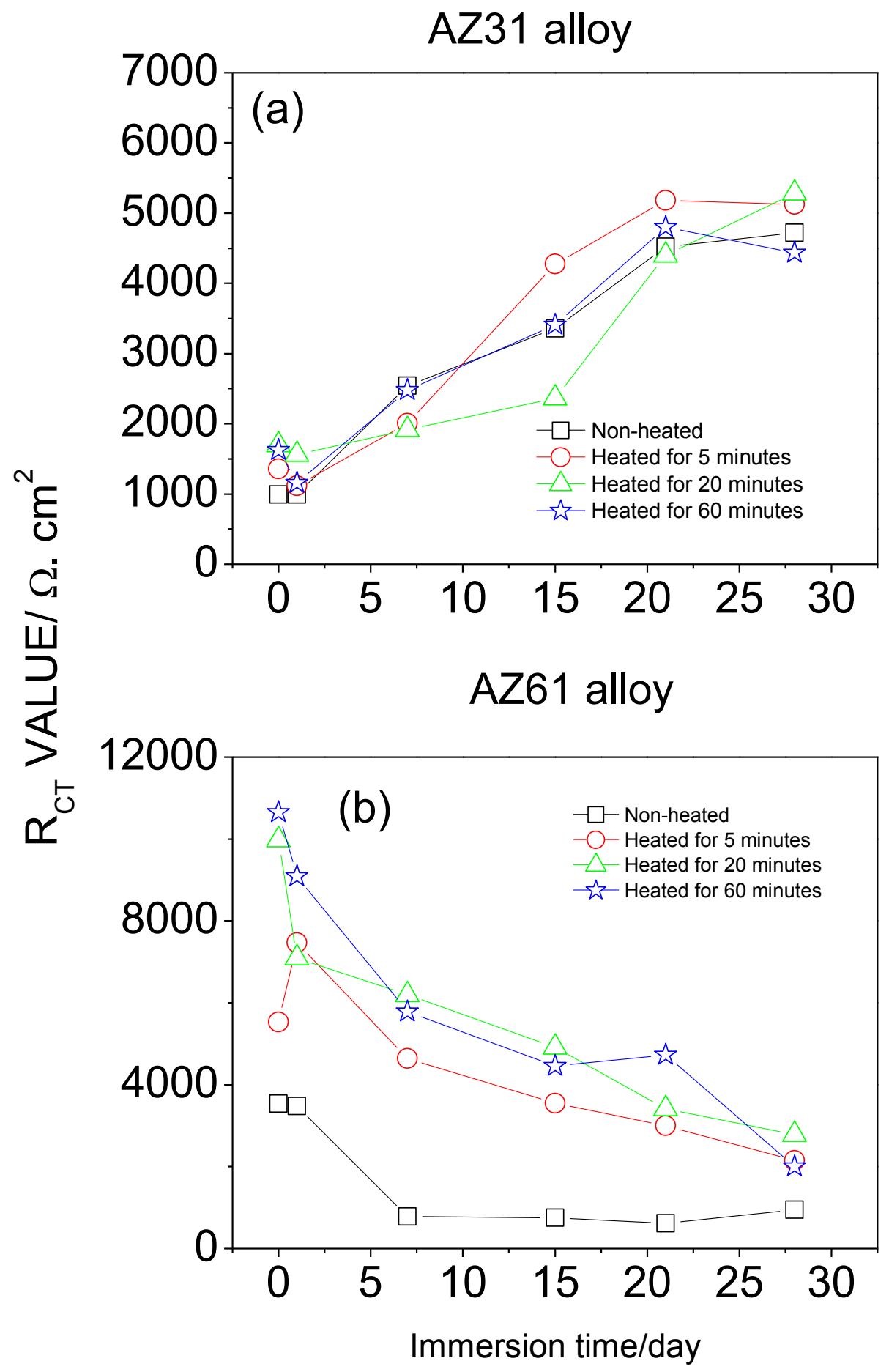

Figure 10. 
$-\square-$ Non-heated

- - - Heated for 5 minutes

Heated for 20 minutes

- 2 - Heated for 60 minutes

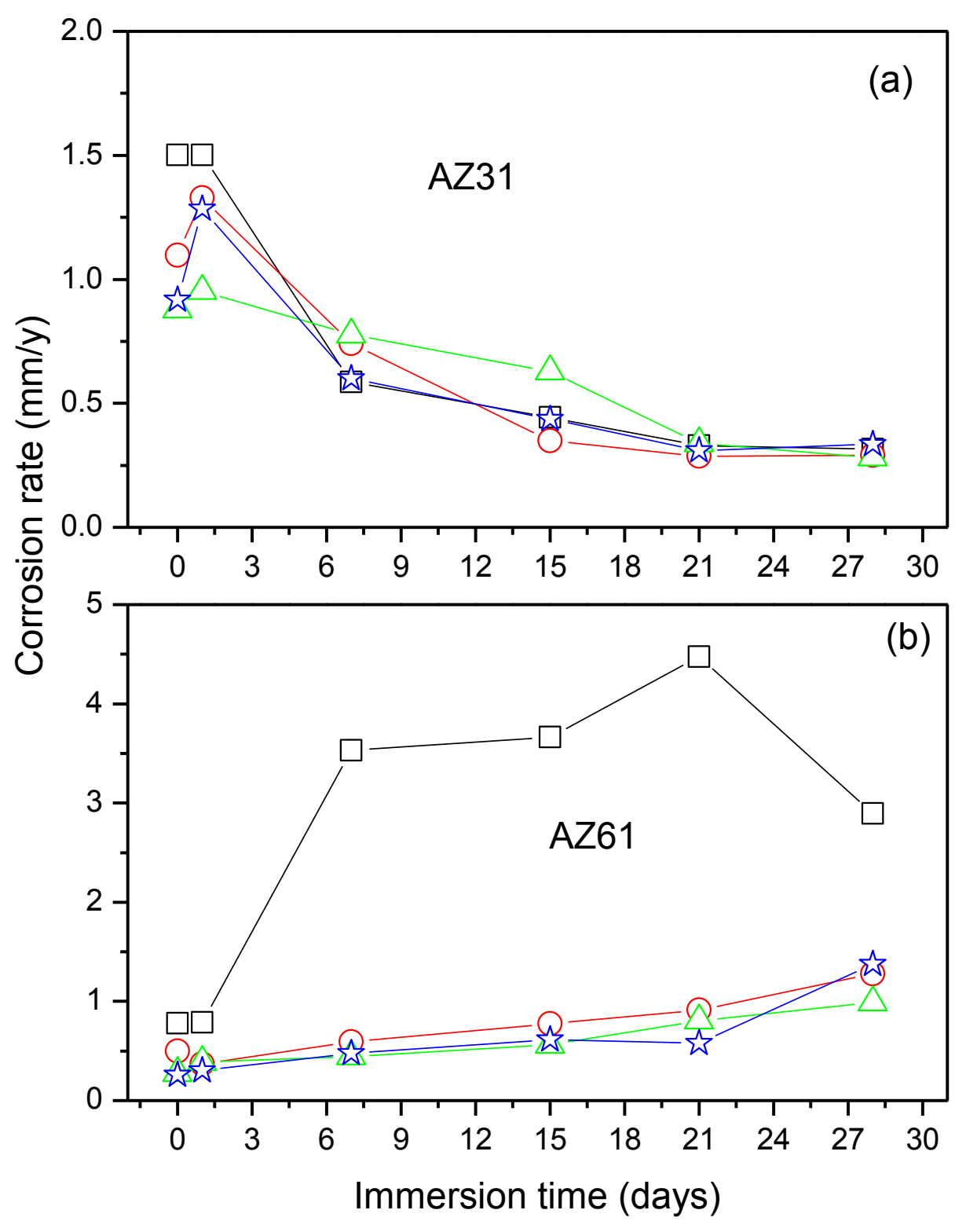

Figure 11. 


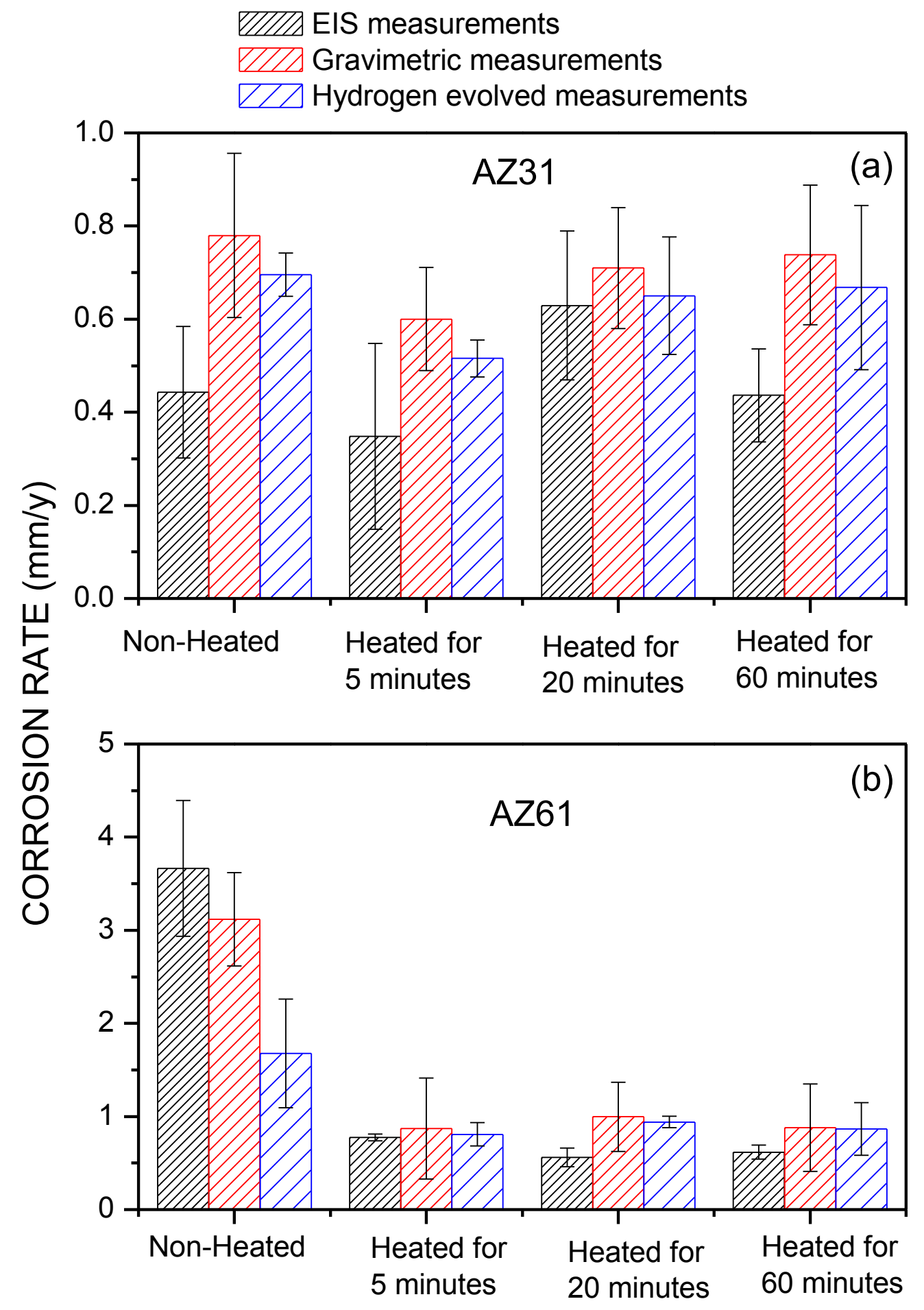

Figure 12. 


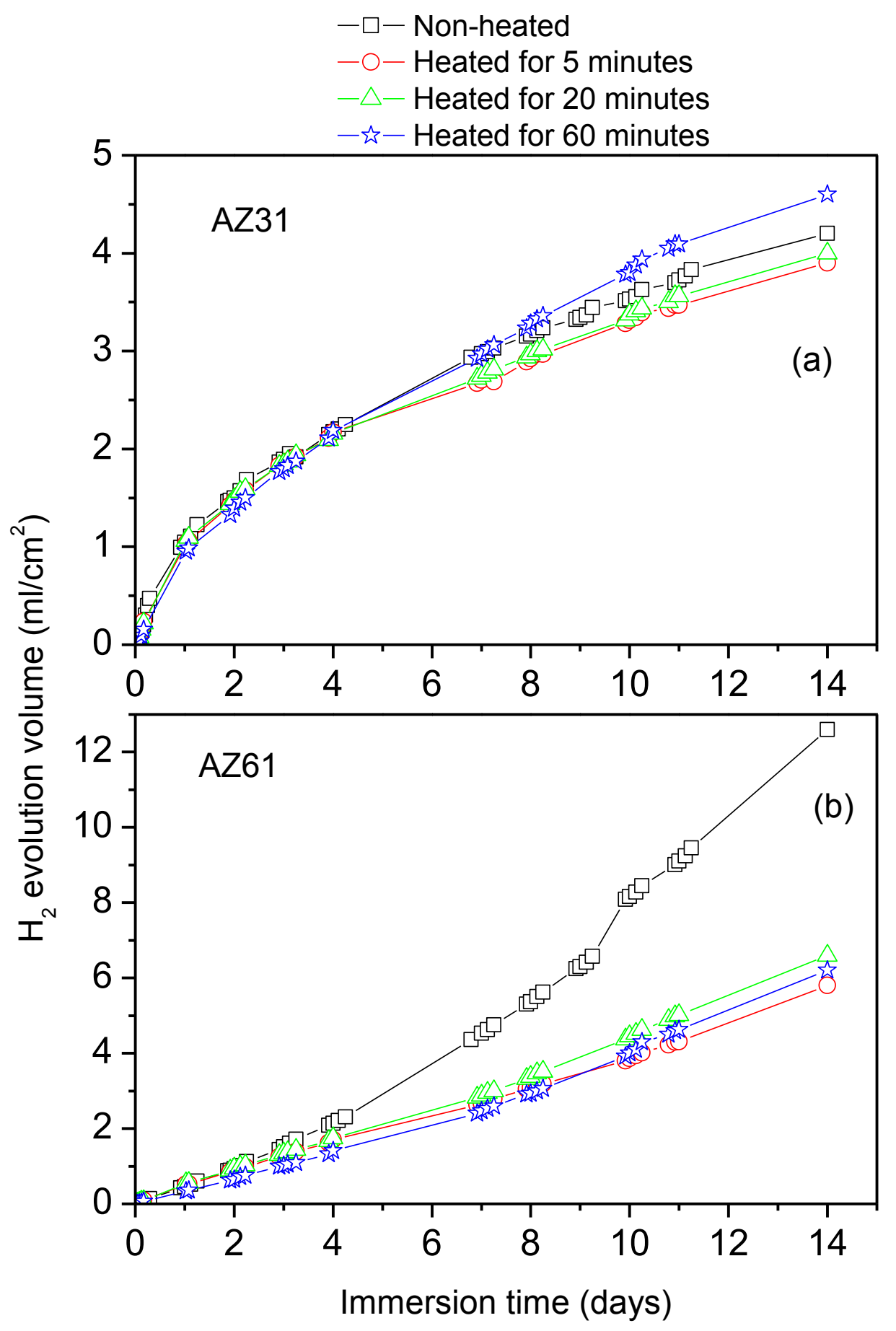

Figure 13. 
Table I. Chemical composition of Mg-Al alloys (wt\%)

\begin{tabular}{|l|l|l|l|l|l|l|l|l|l|l|}
\hline Alloy & Al & Zn & $\mathrm{Mn}$ & $\mathrm{Si}$ & $\mathrm{Cu}$ & $\mathrm{Fe}$ & $\mathrm{Ni}$ & $\mathrm{Ca}$ & $\mathrm{Zr}$ & Others \\
\hline AZ31 & 3.1 & 0.73 & 0.25 & 0.02 & $<0.001$ & 0.005 & $<0.001$ & 0.0014 & $<0.001$ & $<0.30$ \\
\hline AZ61 & 6.2 & 0.74 & 0.23 & 0.04 & $<0.001$ & 0.004 & $<0.001$ & 0.0013 & $<0.001$ & $<0.30$ \\
& & & & & & & & & & \\
\hline
\end{tabular}

